\title{
Retraction Note to: Arbuscular Mycorrhizal Fungi: A Potential Tool for Restoration of Degraded Land
}

Razia Shuab, Rafiq Lone, Javaid Ahmad, and Zafar A. Reshi

\section{Retraction Note to: \\ Chapter "Arbuscular Mycorrhizal Fungi: A Potential Tool for Restoration of Degraded Land" in: Varma et al. (eds.), Mycorrhiza - Nutrient Uptake, Biocontrol, Ecorestoration, https://doi.org/10.1007/978-3-319-68867-1_22}

The Editors have retracted this chapter by Shuab et al. [1] because it shows significant overlap with a previously published article by Asmelash et al. [2]. Razia Shuab, Rafiq Lone, Javaid Ahmad, and Zafar A. Reshi have not responded to any correspondence from the editor/publisher about this retraction.

[1] Shuab R., Lone R., Ahmad J., Reshi Z.A. (2017) Arbuscular Mycorrhizal Fungi: A Potential Tool for Restoration of Degraded Land. In: Varma A., Prasad R., Tuteja N. (eds) Mycorrhiza - Nutrient Uptake, Biocontrol, Ecorestoration. Springer, Cham

[2] Asmelash F, Bekele T and Birhane E (2016) The Potential Role of Arbuscular Mycorrhizal Fungi in the Restoration of Degraded Lands. Front. Microbiol. 7:1095. doi: 10.3389/fmicb.2016.01095

\footnotetext{
The retracted online version of this chapter can be found at
} https://doi.org/10.1007/978-3-319-68867-1_22 